\title{
Structural Investigations of $\alpha$-MnS Nanocrystals and Thin Films Synthesized from Manganese(II) Xanthates by Hot Injection, Solvent-Less Thermolysis, and Doctor Blade Routes
}

\author{
Abdulaziz M. Alanazi, Paul D. McNaughter, Firoz Alam, Inigo J. Vitorica-yrezabal, \\ George F. S. Whitehead, Floriana Tuna, Paul O’Brien, David Collison, and David J. Lewis*
}

Cite This: ACS Omega 2021, 6, 27716-27725

Read Online

ABSTRACT: Manganese(II) xanthate complexes of the form [Mn$\left(\mathrm{S}_{2} \mathrm{COR}\right)_{2}$ (TMEDA)], where TMEDA = tetramethylethylenediamine and $\mathrm{R}=$ methyl (1), ethyl (2), n-propyl (3), n-butyl (4), n-pentyl (5), n-hexyl (6), and noctyl (7), have been synthesized and structures elucidated using single-crystal X-ray diffraction. Complexes 1-7 were used as molecular precursors to synthesize manganese sulfide $(\mathrm{MnS})$. Olelyamine-capped nanocrystals have been produced via hot injection, while the doctor blading followed by thermolysis yielded thick films. Free-standing polycrystalline powders of $\mathrm{MnS}$ are produced by direct thermolysis of precursor powders. All thermolysis techniques produced cubic $\mathrm{MnS}$, as confirmed by powder X-ray diffraction, scanning electron microscopy, energydispersive X-ray spectroscopy, and Raman spectroscopy. Magnetic measurements reveal that the $\alpha$-MnS nanocrystals exhibit ferromagnetic behavior with a large coercive field strength (e.g., $0.723 \mathrm{kOe}$ for $6.8 \mathrm{~nm}$ nanocrystals).

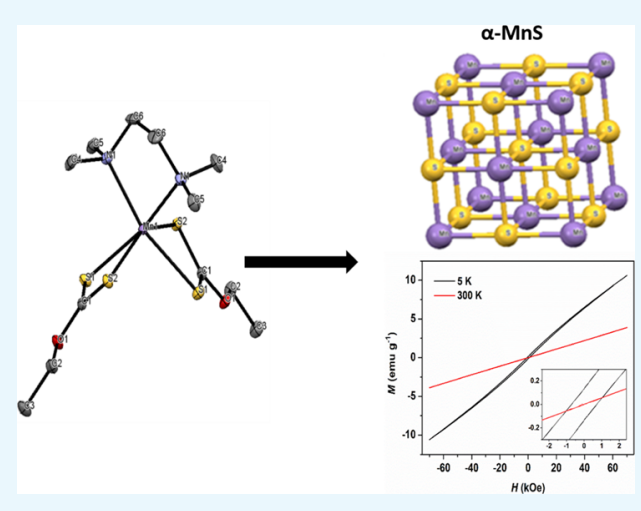

\section{INTRODUCTION}

Nanometric manganese(II) sulfide is an attractive material to target as it possesses useful optical, electrical, and magnetic properties that vary in the nanometer size domain, that is, below $100 \mathrm{~nm} .^{1}$ Manganese sulfide $(\mathrm{MnS})$ is a wide-band-gap $\left(E_{\mathrm{g}} \sim 2.7-3.7 \mathrm{eV}\right)$ p-type semiconductor which exists in three polymorphs: $\alpha, \beta$, and $\gamma$; see Figure 1. $\alpha$-MnS exists in a cubic rock salt and is stable, the $\beta$ form is metastable with a cubic zinc blende structure, and the $\gamma$ phase possesses a metastable hexagonal wurtzite structure. Both $\beta-\mathrm{MnS}$ and $\gamma-\mathrm{MnS}$ can be transformed to the rock salt phase by use of high temperature or high pressure. ${ }^{2}$ Possessing both electronic and magnetic properties allows $\mathrm{MnS}$ to have potential uses in light-emitting and optoelectronic devices, ${ }^{3}$ magneto-optical devices, and as electrodes in lithium ion batteries. ${ }^{4,5}$

At room temperature, all the three bulk phases, $\alpha, \beta$, and $\gamma$, are paramagnetic (PM) and are antiferromagnetic (AFM) below their respective Neél temperatures of 154, 100, and 80 $\mathrm{K}^{6}$ due to the antiferromagnetic coupling of the high-spin $\mathrm{d}^{5}$ $\mathrm{Mn}^{2+}(S=5 / 2)$. With particle sizes decreasing beneath 100 $\mathrm{nm}, \alpha$-MnS displays decreasing $T_{\mathrm{N}}$, which was attributed to a mixture of PM and AFM phases in the nanocrystals (NCs). ${ }^{7}$

A range of synthetic methods have been used to produce $\mathrm{MnS}$ nanostructures including chemical bath deposition, hydrothermal, microwave, solvothermal, and sonochemical methods. $^{9-14}$ Synthetic routes for the controlled synthesis of single-phase MnS NCs have also been reported. ${ }^{15-17}$ For example, Hyeon et al., synthesized hexagonal $\mathrm{MnS}$ by heating a mixture of sulfur and $\mathrm{MnCl}_{2}$ in oleylamine at $280{ }^{\circ} \mathrm{C}$. ${ }^{15}$ Moreover, the use of $\mathrm{Mn}$ (II) dithiocarbamate complexes in the production of manganese sulfide has been reported in a study that examined the effect of the counter anion upon the morphology and phase of the synthesized product. ${ }^{18}$

Metal xanthates are a readily prepared class of precursors that offer a route to a wide variety of metal chalcogenide nanometric materials. ${ }^{19-23}$ Compared to the classic metal dithiocarbamate single-source precursors, metal xanthates thermally decompose at lower temperatures by the Chugaev elimination. ${ }^{24}$ The biproducts formed are SCO, $\mathrm{H}_{2} \mathrm{~S}$, and the corresponding alkene, which are either gasses or volatile liquids, thus lowering the opportunity for contamination of the metal chalcogenide phase formed. Size control over the resulting NCs produced has been observed when increasing the alkyl chain length of the metal xanthate, avoiding the need for additional surfactants. ${ }^{25,26}$

In this work, the novel bis(O-alkylxanthato) manganese(II) complexes (alkyl = Me, Et, ${ }^{n}$ Pr, ${ }^{n}$ But, ${ }^{n}$ Pen, ${ }^{n} \mathrm{Hex}$, and ${ }^{n} \mathrm{Oct}$ ) stabilized by the bidentate $\mathrm{N}$-donor ligand tetramethylethyle-

Received: June 3, 2021

Accepted: August 17, 2021

Published: October 11, 2021 


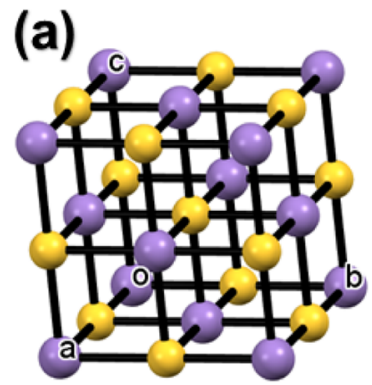

(b)

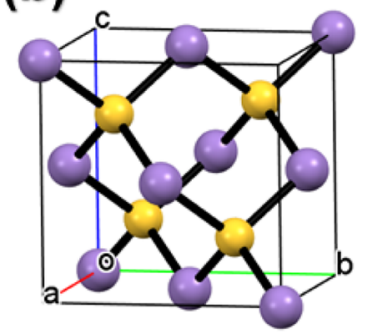

(c)

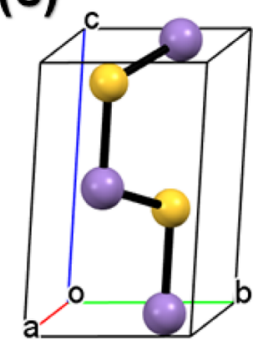

Figure 1. Crystal structures of (a) cubic rock salt (RS) $\alpha$-MnS, $a, b, c=5.224 \AA$ (ICDD 01-089-4952), (b) metastable cubic zinc blende (ZB) $\beta$ $\mathrm{MnS}, \mathrm{a}, \mathrm{b}, \mathrm{c}=5.615 \AA$ (ICDD 00-040-1288), and (c) hexagonal wurtzite (WZ) $\gamma$-MnS structures, $a$ and $b=3.979 \AA$ and $c=6.446 \AA$ (ICDD 00 040-1289). Color code: Mn, violet; S, yellow. Adapted from ref 8, with permission from Elsevier.

nediamine (TMEDA) are synthesized and their crystal structures determined. The complexes are used to produce MnS by three methods: (i) hot injection using oleylamine (OLA) as a capping agent and trioctylphosphine (TOP) as the dispersion medium, (ii) solventless thermolysis to produce free-standing $\mathrm{MnS}$ powders, and (iii) doctor blade for deposition of $\mathrm{MnS}$ films.

\section{RESULTS AND DISCUSSION}

We report here the synthesis and single-crystal structures of six novel manganese xanthates: $\left[\mathrm{Mn}\left(\mathrm{S}_{2} \mathrm{COMe}\right)_{2} \cdot \mathrm{TMEDA}\right](\mathbf{1})$, $\left[\mathrm{Mn}\left(\mathrm{S}_{2} \mathrm{COEt}\right)_{2} \cdot \mathrm{TMEDA}\right](2),\left[\mathrm{Mn}\left(\mathrm{S}_{2} \mathrm{CO}^{n} \mathrm{Pr}\right)_{2} \cdot \mathrm{TMEDA}\right](3)$, $\left[\mathrm{Mn}\left(\mathrm{S}_{2} \mathrm{CO}^{n} \mathrm{But}\right)_{2} \cdot \mathrm{TMEDA}\right](4),\left[\mathrm{Mn}\left(\mathrm{S}_{2} \mathrm{CO}^{n} \mathrm{Pen}\right)_{2} \cdot \mathrm{TMEDA}\right]$ (5), and $\left[\mathrm{Mn}\left(\mathrm{S}_{2} \mathrm{CO}^{n} \mathrm{Hex}\right)_{2} \cdot \mathrm{TMEDA}\right](6) .\left[\mathrm{Mn}\left(\mathrm{S}_{2} \mathrm{CO}^{n} \mathrm{Oct}\right)_{2}\right.$. TMEDA] (7) was also prepared and was characterized only by $\mathrm{X}$-ray diffraction (XRD) analysis, elemental analysis, and melting point. These complexes were prepared from the reaction of a previously prepared potassium alkylxanthate and manganese(II) acetate tetrahydrate with the subsequent addition of TMEDA. All the complexes were soluble in common organic solvents such as chloroform, tetrahydrofuran (THF), and toluene. The complexes were stored at $-20{ }^{\circ} \mathrm{C}$ to prevent decomposition. The structures of the complexes are shown in Figure 2. 2, 3, 4, 6, and 7 adopt monoclinic crystal systems with space groups $C 2 / c, P 2_{1} / c, P 2_{1} / c, I 2 / a$, and $I 2 / a$, respectively, while $\mathbf{1}$ is orthorhombic $P b c a$ and $\mathbf{5}$ is triclinic $P \overline{\mathbf{1}}$.

In all cases, the central $\mathrm{Mn}$ ions were coordinated by six atoms, bound by two xanthate ligands and single TMEDA ligand, with $\mathrm{N}$ and $\mathrm{S}$ donors arranged in a distorted octahedron. Furthermore, no differences in $\mathrm{Mn}-\mathrm{S}$ or $\mathrm{Mn}-\mathrm{N}$ bond distances were observed within the structures of 2, 6, and 7; therefore, the ligands were considered to be in a symmetric (isobidentate) mode. However, the $\mathrm{Mn}-\mathrm{N}$ bond distances in $\mathbf{5}$ were significantly different, and a relatively small difference was observed in the cases of 1, 3, and 4; therefore, the ligands were considered to be in an asymmetric mode, as presented in Table S1.

The molecular structure of 2, $\left[\mathrm{Mn}\left(\mathrm{S}_{2} \mathrm{COCH}_{2} \mathrm{CH}_{3}\right)_{2}\right.$. (TMEDA)], is shown in Figure 2, and the selected geometric parameters are presented in Table S2. The shorter Mn-S and the longest $\mathrm{Mn}-\mathrm{S}$ bond lengths involving the xanthate ligands were 2.5645 and $2.6750 \AA$, respectively, as listed in Table S1, and were in good agreement with those reported for other analogous 1:1 adducts of $\mathrm{Mn}$-dithiocarbonato (xanthate) complexes. $^{27}$

The symmetric mode of coordination of the xanthate ligands was reflected in the near equivalence of the associated $\mathrm{C}-\mathrm{S}$ bond distances. Within each of the xanthate ligands, the shorter $\mathrm{Mn}-\mathrm{S}$ bond had the $\mathrm{S}$ atom approximately trans to a $\mathrm{N}$ atom, and the two $\mathrm{S}$ atoms forming the longer $\mathrm{Mn}-\mathrm{S}$ bonds were approximately trans to each other. Another difference between the structures was that the shortest $\mathrm{Mn}-\mathrm{N}$ bond distance was observed in complex 6, and thus, the $\mathrm{N}-\mathrm{Mn}-\mathrm{N}$ angle was the shortest angle compared with other complexes.

As the alkyl chain length increased in the structures with identical binding of the two xanthates to the $\mathrm{Mn}$, the difference in the bonding modes of the two ligands became more obvious. The difference in the $\mathrm{Mn}-\mathrm{S}$ bond distances in the symmetrical binding decreased with an increase in the length of the alkyl chain. The $\Delta(\mathrm{Mn}-\mathrm{S})=$ (longer $\mathrm{Mn}-\mathrm{S}$ bond distance - shorter $\mathrm{Mn}-\mathrm{S}$ distance) values for the remaining ligand were $0.11,0.08$, and $0.03 \AA$ for 2,6 , and 7, respectively. In contrast, the difference in the $\mathrm{Mn}-\mathrm{S}$ bond distances in the asymmetric binding of $1,3,4$, and 5 displayed no trend with increase in the alkyl chain length.

The relatively short $\mathrm{C}-\mathrm{O}$ bond distances of 1.333 (2) $\AA$ for one ligand in complexes $1,2,3,4$, and 5 were almost the same. However, in 6 and 7, the $\mathrm{C}-\mathrm{O}$ bond distances were 1.361 (5) and 1.341 (9) $\AA$, respectively, which were longer than those of the other complexes. The data shown in Table S1 are consistent with a significant contribution of the resonance form of the xanthate anion that features a formal $\mathrm{C}=\mathrm{O}$ bond and the negative charges on each of the $S$ atoms. In the case of compound 2, the bidentate $\mathrm{N}$-donor ligands had the same $\mathrm{Mn}-\mathrm{N} 1$ and Mn-N2 distances (2.293 (15) Å). Because of the restricted ligand bite, the angles $\mathrm{N}-\mathrm{Mn}-\mathrm{N}$ and $\mathrm{S}-\mathrm{Mn}-\mathrm{S}$ were lower than $90^{\circ}$ in a regular octahedron. The $\mathrm{N}-\mathrm{Mn}-\mathrm{N}$ angles averaged at approximately $79.22^{\circ}$ (8) and S-Mn-S angles at $69.10^{\circ}(15)$, as shown in Table S1. The molecular structures of other novel complexes are shown in Figure 2, and selected bond distances and angles are given in Table S1.

The most distinct difference between these compounds was how the ligand frameworks and the presence of hydrogen bonds affected the crystal packing in the extended solid state for all of these complexes. As shown in Figure S1, all the complexes displayed intermolecular hydrogen bonds through the sulfur atoms of the neighboring molecules $(\mathrm{C}-\mathrm{H} \cdots \mathrm{S})$, while in the complex 4, the $\mathrm{C}-\mathrm{H} \cdots \mathrm{S}$ interaction linked a molecule with another one by the $\mathrm{H}$ from the TMEDA, except complex 5, wherein the $(\mathrm{C}-\mathrm{H} \cdots \mathrm{S})$ interaction was not observed. The distances of these interactions were slightly shorter than the sum of the contact radii (van der Waals radii), ${ }^{28}$ as shown in Table $\mathrm{S} 3$.

Furthermore, 2, 3, and 6 had two main modes of association between molecules; one of them was the $\mathrm{H}$ from the adduct contact with the $\mathrm{S}$ from the other molecule $(\mathrm{N}-\mathrm{C}-\mathrm{H} \cdots \mathrm{S})$ and 

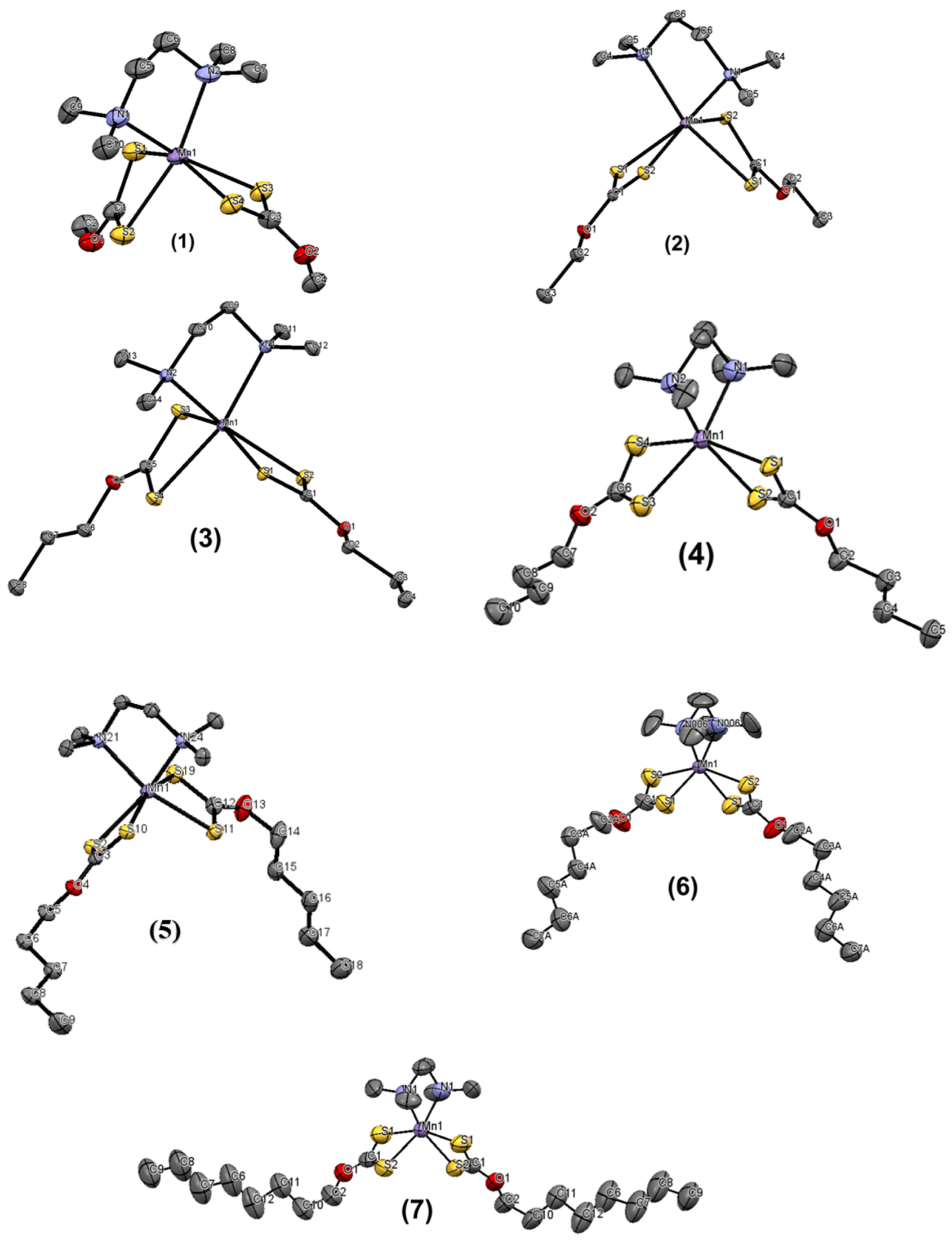

Figure 2. Molecular structures of $\left[\mathrm{Mn}\left(\mathrm{S}_{2} \mathrm{COMe}\right)_{2} \cdot \mathrm{TMEDA}\right](\mathbf{1}), \quad\left[\mathrm{Mn}\left(\mathrm{S}_{2} \mathrm{COEt}\right)_{2} \cdot \mathrm{TMEDA}\right](2),\left[\mathrm{Mn}\left(\mathrm{S}_{2} \mathrm{CO}{ }^{n} \mathrm{Pr}\right)_{2} \cdot \mathrm{TMEDA}\right](3),[\mathrm{Mn}$ $\left.\left(\mathrm{S}_{2} \mathrm{CO}^{n} \mathrm{But}\right)_{2} \cdot \mathrm{TMEDA}\right](4),\left[\mathrm{Mn}\left(\mathrm{S}_{2} \mathrm{CO}^{n} \mathrm{Pen}\right)_{2} \cdot \mathrm{TMEDA}\right](5),\left[\mathrm{Mn}\left(\mathrm{S}_{2} \mathrm{CO}^{n} \mathrm{Hex}\right)_{2} \cdot \mathrm{TMEDA}\right](6)$, and $\left[\mathrm{Mn}\left(\mathrm{S}_{2} \mathrm{CO}^{n} \mathrm{Oct}\right)_{2} \cdot \mathrm{TMEDA}\right](7)$. $\mathrm{H}$ atoms are omitted for clarity. Violet $=\mathrm{Mn}$, yellow $=\mathrm{S}$, red $=\mathrm{O}$, blue $=\mathrm{N}$, and gray $=\mathrm{C}$. $($ CCDC 1959720-1959726). 
the $\mathrm{H}$ from the alkyl group contact with $\mathrm{S}$ from the other molecule $(\mathrm{C}-\mathrm{C}-\mathrm{H} \cdots \mathrm{S})$, as shown in Figure S1. In contrast, $\mathbf{1}$ and 7 had one mode of association between molecules, which was the $(\mathrm{N}-\mathrm{C}-\mathrm{H} \cdots \mathrm{S})$ interaction in $\mathbf{1}$ and the $(\mathrm{C}-\mathrm{C}-\mathrm{H} \cdots \mathrm{S})$ interaction in complex 7 . The complex 5 also exhibited interchelate distances between $S$ from the molecule and $S$ from another molecule (3.491 $\AA$ ).

Thermal analyses of all the complexes were conducted up to $600{ }^{\circ} \mathrm{C}$ under nitrogen; see Figure 3 . Complexes 1, 2, 3, and 4

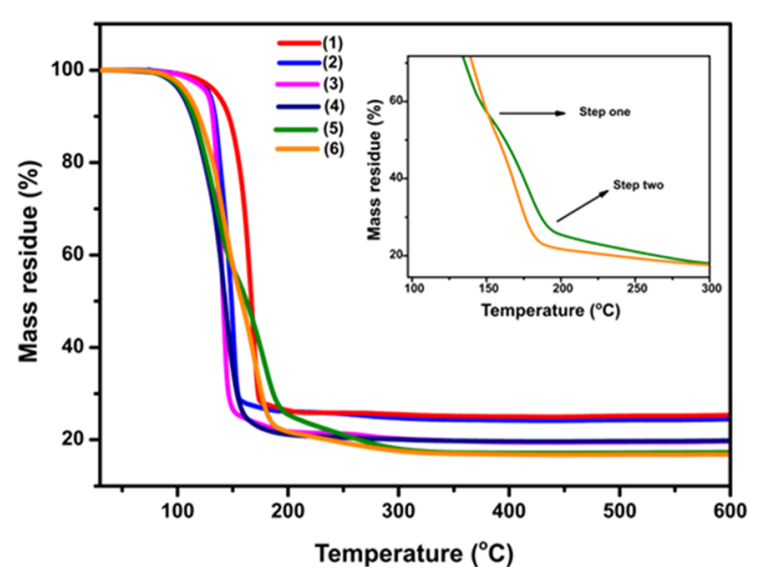

Figure 3. TGA profiles of complexes (1-6).

showed a one-step decomposition to form $\mathrm{MnS}$, with the decomposition profile shifting to lower temperature with increase in the precursor alkyl chain length. For chain lengths of pentyl and above, the thermogravimetric analysis (TGA) profiles displayed a two-step breakdown. In the case of $\mathbf{5}$ and $\mathbf{6}$ precursors, the mass residue obtained from the TGA profiles for the first decomposition stage (57.5\%) agrees with the theoretical value calculated for the removal of one molecule of xanthate and half from a second (58\%). All the six complexes gave the final solid residue amounts that matched with the predicted value for $\mathrm{MnS}$; see Table S4.

MnS NCs Using the Hot-Injection Method. MnS NCs were synthesized using hot injection of manganese alkylxanthate in TOP and then injected into preheated OLA at $230{ }^{\circ} \mathrm{C}$. OLA is used as a coordinating agent and also can catalyze the degradation of complexes at lower temperatures than the other methods. $^{29,30}$ It was observed that complex 2 showed partial decomposition at $200{ }^{\circ} \mathrm{C}$, leading to poor crystallinity of the material produced; see Figure S3. $250{ }^{\circ} \mathrm{C}$ yielded a material with good crystallinity, as shown by the $p$-XRD measurements, Figure 4, with reflections corresponding to cubic $\alpha$-MnS (JCPDS 03-065-0891). The diffraction patterns showed significant changes in the intensity of peaks depending on the chain length. For complexes from 2 to 4 , the fall in intensity with the precursor chain length was greater in the (220) plane.

Estimated crystallite sizes using the Scherrer equation were found to be 19.5, 17.8, 17.0, 14.9, 10.0, and $9.2 \mathrm{~nm}$ for $\mathrm{MnS}$ NCs from precursors 1, 2, 3, 4, 5, and 6, respectively; see details in Supporting Information. Kan et al. have successfully synthesized cubic $\alpha$-MnS NCs of different sizes ranging from 20 to $80 \mathrm{~nm}$ by a colloidal synthesis route through the reaction of $\mathrm{MnCl}_{2}$ and $\mathrm{S}\left[\mathrm{Si}\left(\mathrm{CH}_{3}\right)_{3}\right]_{2}$ in trioctylphosphineoxide. ${ }^{7}$ The calculated lattice parameters and volume are given in Table S5.

The atomic percentages of the samples prepared by hot injection were determined by energy-dispersive X-ray (EDX)

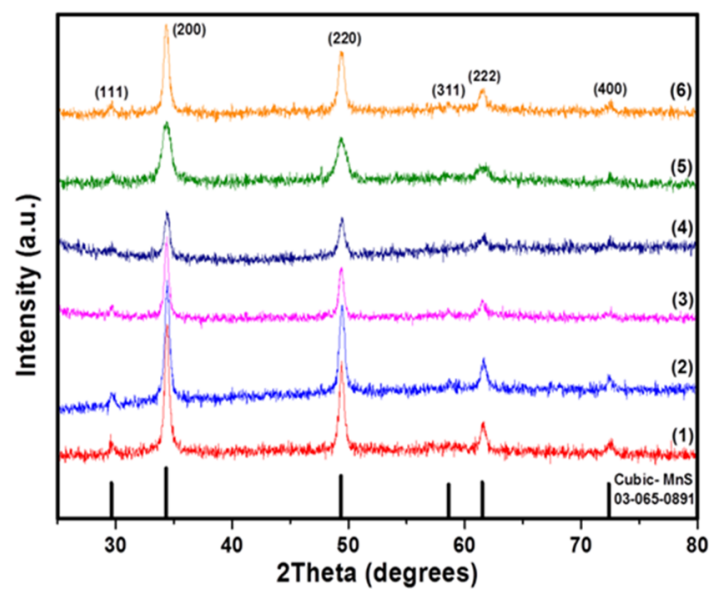

Figure 4. XRD patterns of $\mathrm{MnS}$ prepared at $250{ }^{\circ} \mathrm{C}$ via hot injection from precursors $\mathbf{1 - 6}$. The standard pattern (black sticks) is cubic $\alpha$ MnS (ICDD no. 03-065-0891).

spectroscopy, showing the composition to be approximately 50:50 of $\mathrm{Mn}$ and $\mathrm{S}$ and suggesting that manganese sulfide was formed (Supporting Information Figure S4, Table S5†).

The morphology of the synthesized MnS NCs was observed by scanning electron microscopy (SEM), and the images are shown in Figure 5. The MnS NCs obtained from 1-5 have irregular shapes (Figure $5 \mathrm{a}-\mathrm{e}$ ), while those obtained from complex $\mathbf{6}$ have a more regular morphology across the sample (Figure 5f).

Raman spectroscopy revealed that the MnS synthesized via hot injection from precursor $\mathbf{1}$ exhibited a single band at $635.89 \mathrm{~cm}^{-1}$ and remains approximately the same for precursors 2, 3, 4, 5, and 6, which is in agreement with reported values; see Figure S5 and Table S5. ${ }^{31}$

MnS NCs Using Solventless Thermolysis. At lower temperatures of 250 and $300{ }^{\circ} \mathrm{C}$, the complete conversion of 2 $\left[\mathrm{Mn}\left(\mathrm{S}_{2} \mathrm{COEt}\right)_{2} \cdot(\mathrm{TMEDA})\right]$ had not occurred when observed by XRD (Figure S7), whereas at $350{ }^{\circ} \mathrm{C}$, good crystallinity demonstrated that complete conversion occurred.

With heating for $1 \mathrm{~h}$ at $350{ }^{\circ} \mathrm{C}$, all six precursors (1-6) generated $\mathrm{MnS}$, with patterns that are in good agreement with the cubic $\alpha$-MnS phase (JCPDS 03-065-0891, Figure 6). Crystallite size was estimated with the Debye-Scherrer equation to be $8.2,6.8,6.3,8.9,7.6$, and $8.7 \mathrm{~nm}$ for NCs obtained from 1, 2, 3, 4, 5, and 6, respectively (Table S6).

For precursors 1 and 2, the NCs were found to be aggregates consisting of numerous particles (Figure $7 \mathrm{a}, \mathrm{b}$ ). For precursors $3-6$, the products are irregular in appearance (Figure $7 c-f$ ). The atomic percentages of the NCs obtained from EDX from all the precursors $(\mathbf{1 - 6})$ are shown in Figure S9 and Table S6.

Raman spectroscopy revealed that the $\mathrm{MnS}$ synthesized from precursor 1 by solventless thermolysis exhibited a band at $635.18 \mathrm{~cm}^{-1}$ which varied insignificantly when using precursors 2, 3, 4, 5, and 6 (Figure S10 and Table S6), as previously reported. ${ }^{31}$

MnS Thin Films by Doctor Blading. The diffraction peaks of the thin films prepared from complexes 1-6 were indexed to cubic manganese sulfide, $\alpha-\mathrm{MnS}$ (ICDD \# 03-0650891); see Figure 8. The patterns showed a change in the intensity compared to the bulk pattern that indicated a preferred growth in the (200) and (220) planes at $2 \theta=34.4$ and $49.4^{\circ}$, respectively, which exists and shows an increase with the precursor chain length. This suggests that the 

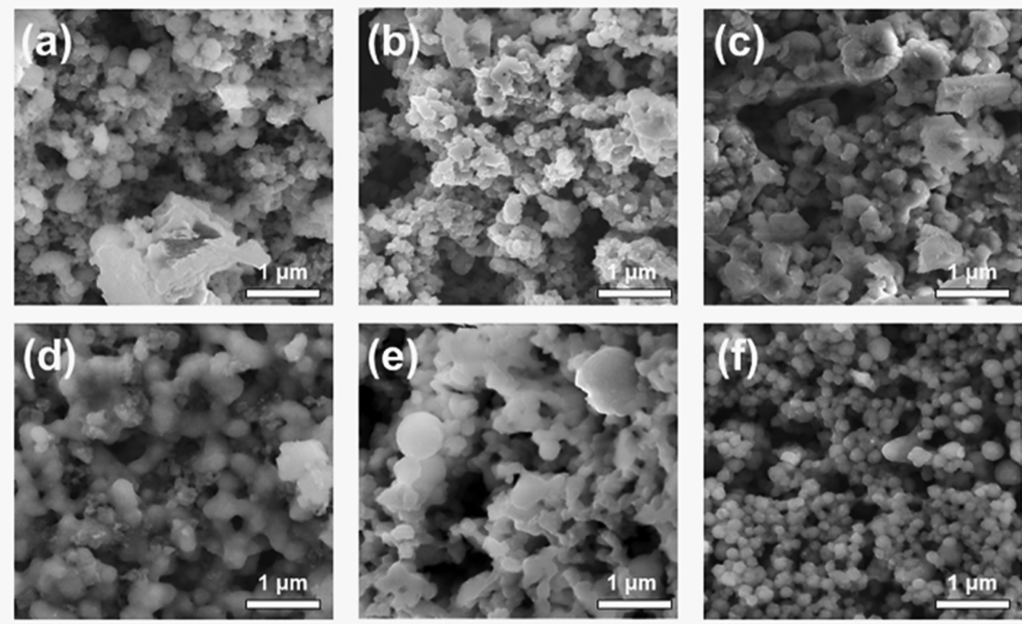

Figure 5. Representative secondary electron SEM images $(10 \mathrm{kV})$ of $\mathrm{MnS}$ samples prepared using precursors (a-f) (1-6) prepared by the hot injection method at $250{ }^{\circ} \mathrm{C}$.

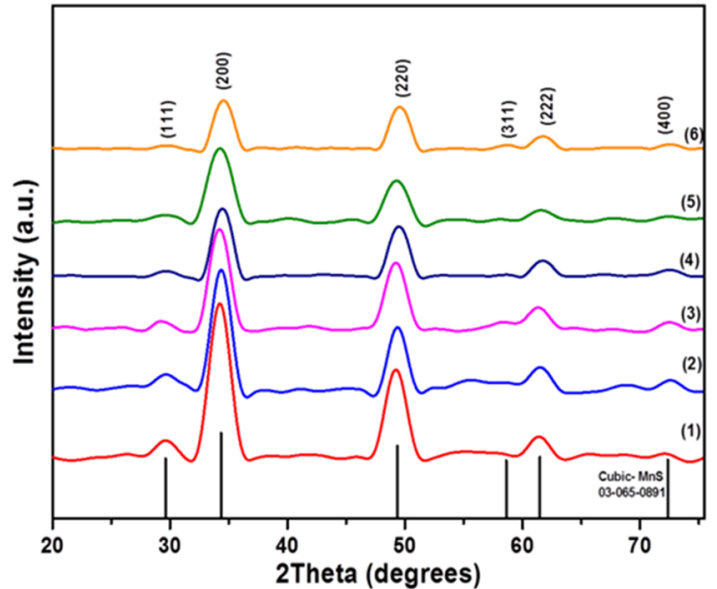

Figure 6. $p$-XRD patterns of $\mathrm{MnS}$ prepared at $350{ }^{\circ} \mathrm{C}$ via solventless thermolysis of precursors $(1-6)$. The standard pattern is cubic manganese sulfide, MnS (ICDD no. 03-065-0891).

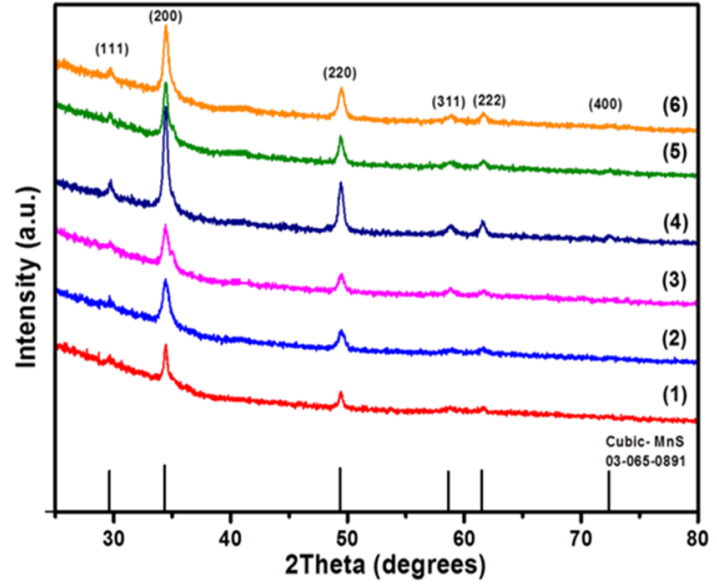

Figure 8. XRD patterns of $\mathrm{MnS}$ thin films prepared by the doctor blade method and heated at $350{ }^{\circ} \mathrm{C}$ from precursors $1-6$. The standard pattern shown is cubic manganese sulfide, MnS (ICDD no. 03-065-0891).
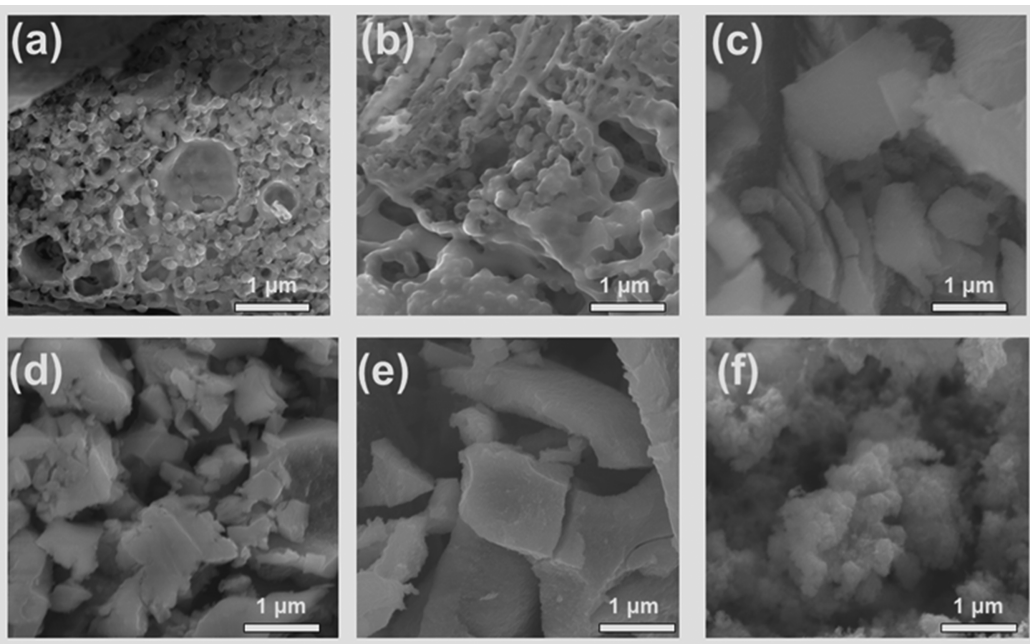

Figure 7. Representative secondary electron SEM images $(10 \mathrm{kV})$ of $\mathrm{MnS}$ samples produced using precursors (a-f) (1-6) and prepared by solventless thermolysis at $350{ }^{\circ} \mathrm{C}$. 

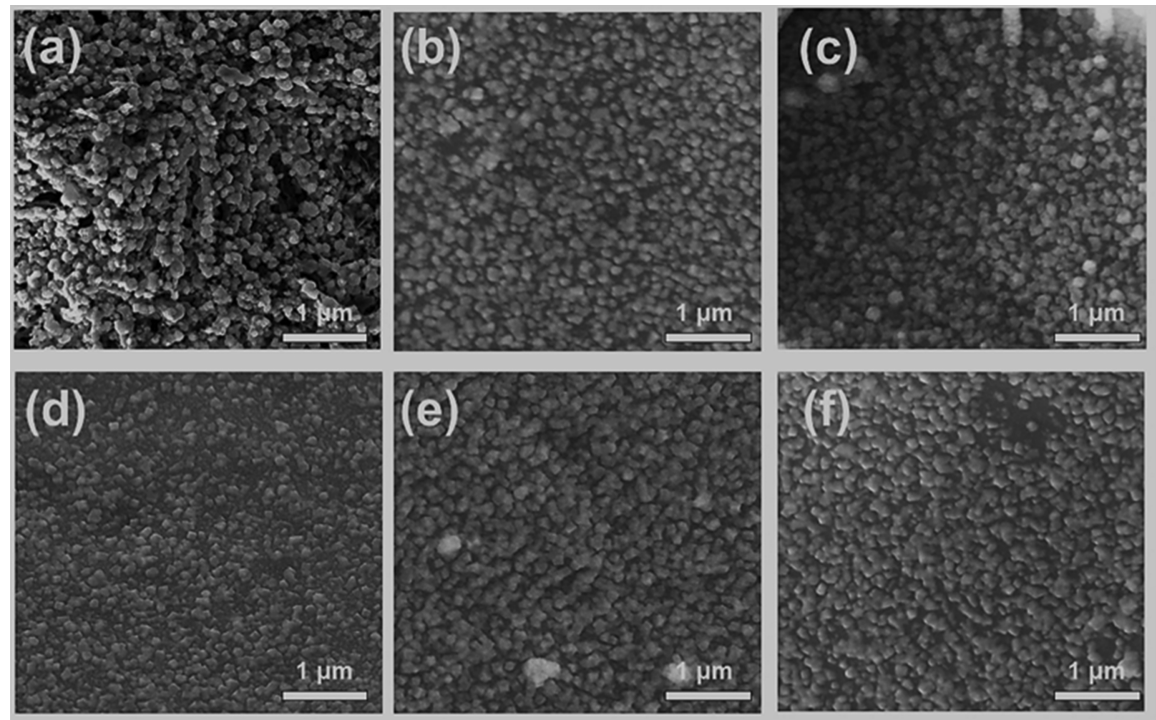

Figure 9. Secondary electron SEM images $(10 \mathrm{kV})$ of $\mathrm{MnS}$ thin films using precursors $(\mathrm{a}-\mathrm{f}) \mathbf{1}-\mathbf{6}$ deposited by the doctor blade method at $350{ }^{\circ} \mathrm{C}$.

molecular precursor structure influences the nucleation and growth of manganese sulfide thin films under these conditions. Using the Debye-Scherrer equation, the width of the crystallites was found to be $20.8,14.2,13.4,17.6,16.5$, and $16.5 \mathrm{~nm}$ for the thin films obtained from the complexes $1,2,3$, 4, 5, and 6, respectively (Table S7). The sizes of the crystallites are similar to those obtained by using the hot injection method but are larger than those when using the solventless thermolysis. Crystallites that have preferred orientation have been observed in other studies of thin films grown by the chemical bath deposition technique. ${ }^{32}$

All precursors resulted in thin films of cubic MnS; see Figure $9 \mathrm{a}-\mathrm{d}$. The morphologies of the films from the doctor blade method were significantly different to those from hot injection and solventless thermolysis. EDX spectroscopy revealed the presence of manganese and sulfur in near stoichiometric amounts in all samples (Figures S11 and S7).

Raman spectroscopy revealed that the MnS thin films obtained from the precursors 1, 2, 3, 4, 5, and 6 all exhibited bands at approximately $635.89 \mathrm{~cm}^{-1}$ (Figure S12 and Table S7) and are in agreement with that of bulk MnS. ${ }^{31}$

Magnetic Properties of MnS NCs. The magnetic properties of the $\alpha$-MnS obtained from complex 2 using solventless thermolysis were studied. The room-temperature $\mathrm{X}$-band EPR spectrum of $\alpha$-MnS NCs obtained from complex 2 displays a strong signal with $g=2$, characteristic of magnetic NCs (Figure 10). The magnetization of the NCs was measured as a function of temperature, in field-cooled (FC) and zerofield-cooled (ZFC) regimes, under an applied field of $100 \mathrm{Oe}$ (Figure 11). The magnetic properties of $\alpha$-MnS NCs have been investigated by Kan et al., where at different sizes between 20 and $80 \mathrm{~nm}, \alpha$-MnS NCs were antiferromagnetic (AFM) with reduced interaction strength in smaller NCs. However, these NCs were aggregates with smaller particles, which led to their hysteresis loop being closed. ${ }^{7}$ Puglisi et al. reported the magnetic properties of single-crystal octahedral $\alpha$-MnS NCs of different sizes $(14,20$, and $29 \mathrm{~nm})$. Below $50 \mathrm{~K}$, the NCs showed increase in FC magnetization and a maximum ZFC magnetization at $25 \mathrm{~K}$, which both confirmed of a transition between a superparamagnetic (SPM) and ferromagnetic (FM) type. $^{16}$

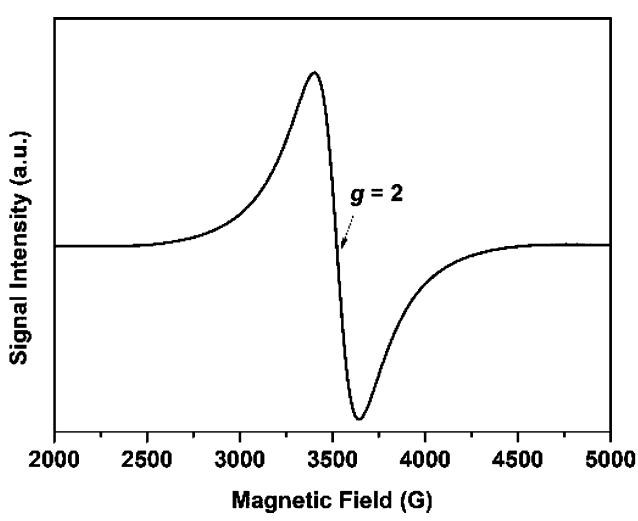

Figure 10. X-band EPR spectrum of $\alpha$-MnS NCs obtained from complex 2 .

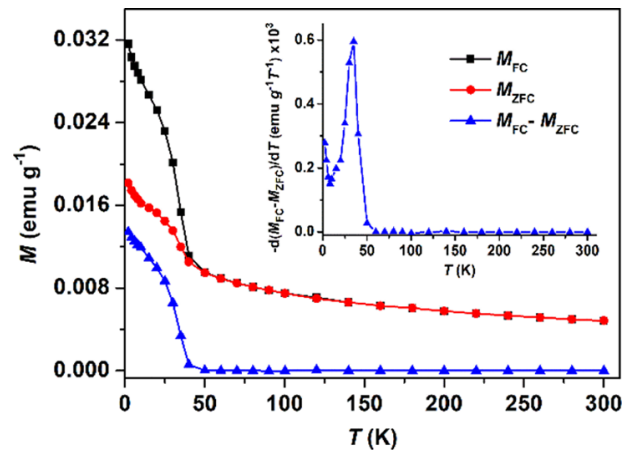

Figure 11. Thermal dependence of magnetization for $\alpha$-MnS NCs obtained from complex 2, measured in ZFC (red circles) and FC (black squares) regimes, with the difference $M_{\mathrm{FC}}-M_{\mathrm{ZFC}}$ plotted in blue. Inset: plot of $-\mathrm{d}\left(M_{\mathrm{FC}}-M_{\mathrm{ZFC}}\right) / \mathrm{d} T$ for the same NCs.

Irreversible magnetic behavior is observed below $40 \mathrm{~K}$, which marks a transition from the SPM to FM, the latter characterized by blocking of magnetization. The presence of FM-like regions in the material is also evident in the $T$ dependence of the magnetization difference in Figure 11 (blue triangles). Above $70 \mathrm{~K}$, the $\mathrm{ZFC}$ and $\mathrm{FC}$ magnetization curves fully superpose and data could be fitted to a Curie-Weiss law, 
$\chi=C /(T-\theta)$, providing a Curie-Weiss constant $\theta=-254 \mathrm{~K}$ (Figure 12).

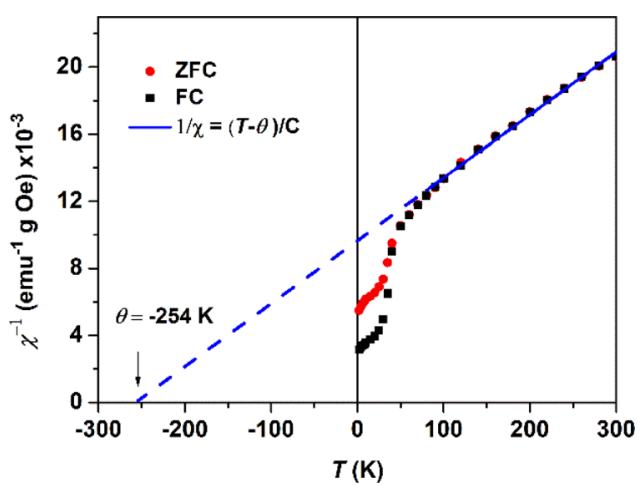

Figure 12. Plot of $1 / \chi$ vs temperature for $\alpha$-MnS NCs obtained from complex 2, measured in ZFC (red) and FC (black) regimes, with a fit to the Curie law $\chi=C /(T-\theta)$ represented in blue (dashed lines).

The negative sign of $\theta$ indicates that the $\alpha$-MnS NCs obtained from 2 are antiferromagnetic. The $\theta$ value is less negative than the bulk value of $-465 \mathrm{~K}^{33}$ and close to the value that was reported by Puglisi et al., where $\theta=-272 \mathrm{~K}$ for 29 nm. ${ }^{16}$ The AFM interactions become less effective for smaller NCs, approximately in agreement with previous results. The existence of the FM structure at the surface of the $\alpha-\mathrm{MnS}$ NCs is additionally supported by the hysteresis measured at 5 and $300 \mathrm{~K}$, as shown in Figure 13. At $300 \mathrm{~K}$, the saturated

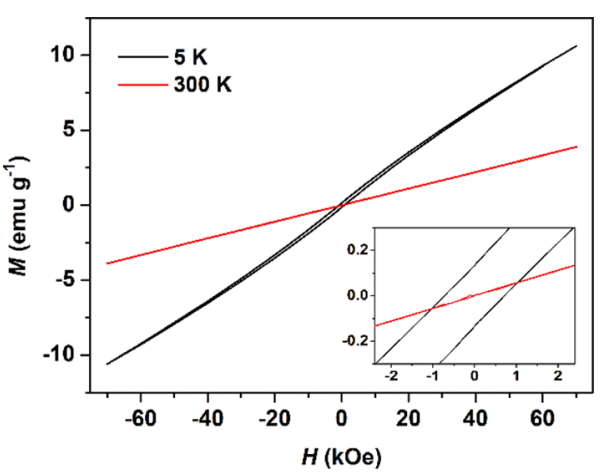

Figure 13. Magnetic hysteresis at 5 and $300 \mathrm{~K}$ for $\alpha$-MnS NCs obtained from 2 . The inset shows the region around zero fields.

magnetization was smaller than $5 \mathrm{~K}$, and there were no hysteresis loops. The hysteresis curve recorded at $5 \mathrm{~K}$ shows that the magnetization does not saturate up to the magnetic field of $70 \mathrm{kOe}$, indicative of large anisotropy. Cycling of the magnetization between 70 and $-70 \mathrm{kOe}$ reveals a hysteresis loop with a coercive field, $H_{c}$, of $0.723 \mathrm{KOe}$. This field is larger than that observed for similar NCs. Puglisi et al. confirmed that $\alpha$-MnS NC samples obtained by isothermal magnetization at 5 $\mathrm{K}$ showed an open loop with size-dependent $H_{\mathrm{c}}$ of $0.009 \mathrm{kOe}$ $(14 \mathrm{~nm}), 0.081 \mathrm{kOe}(20 \mathrm{~nm})$, and $0.180 \mathrm{kOe}(29 \mathrm{~nm}) .{ }^{16}$ Yang et al. reported that at low temperature, hysteresis loops were presented in the FM region since they displayed open loops with size-dependent $H_{\mathrm{c}}$ ranging from $0.01 \mathrm{kOe}(14 \mathrm{~nm})$ to $1.265 \mathrm{kOe}(40 \mathrm{~nm}))^{3}$ This result is, to the best of our knowledge, the first demonstration of a large coercive field $(0.723 \mathrm{kOe}$ at $5 \mathrm{~K}$ with small size of $6.8 \mathrm{~nm})$ in $\alpha$-MnS NCs. It is noted that the magnetization of FM materials depends on the size, shape, and structure of these materials. ${ }^{34}$

\section{CONCLUSIONS}

The synthesis and the single-crystal X-ray structure of seven novel tetramethylethylenediamine manganese(II) bis(alkylxanthate) complexes in which the alkyl group was methyl (1), ethyl (2), n-propyl (3), n-butyl (4), n-pentyl (5), n-hexyl (6), and n-octyl (7)] were reported. Complexes 2, 3, 4, 6, and 7 adopted the monoclinic crystal system, while 1 was orthorhombic and $\mathbf{5}$ was triclinic. All the compounds displayed intermolecular hydrogen bonds through the sulfur atoms of the neighboring molecules $(\mathrm{C}-\mathrm{H} \cdots \mathrm{S})$, except complex 5, wherein the $(\mathrm{C}-\mathrm{H} \cdots \mathrm{S})$ interaction was not observed. The distances of these interactions were slightly shorter than the sum of the contact radii (van der Waals radii). Furthermore, 4 and 5 exhibited intramolecular S-S distances of 3.491 and $3.565 \AA$, respectively.

Hot injection with OLA lowered the relative decomposition temperatures of the precursors, whereas the solventless thermolysis and the doctor blade technique required a higher decomposition temperature of $350{ }^{\circ} \mathrm{C}$. XRD studies showed that all the precursors broke down cleanly at 250 and $350{ }^{\circ} \mathrm{C}$ by all methods to form cubic nanoscale $\alpha-\mathrm{MnS}$ with sizes dependent on the breakdown method used. Magnetic measurements revealed that these nanomaterials possess a large coercive field $(0.723 \mathrm{kOe}$ for $6.8 \mathrm{~nm} \mathrm{NCs})$ in contrast to other studies of nanometric $\mathrm{MnS}$ reported in the literature.

\section{EXPERIMENTAL SECTION}

Materials and Instrumentation. All chemicals were purchased from Sigma Aldrich or Alfa Aesar and used as received. Melting points were determined with a Stuart melting point apparatus (Cole-Parmer, UK). Infrared spectra (IR) were recorded using a Nicolet iS5 Thermo Scientific ATR instrument in the range $4000-400 \mathrm{~cm}^{-1}$ and with a spectral resolution of $4 \mathrm{~cm}^{-1}$. Elemental analysis (EA) and TGA were carried out by the Micro-elemental Analysis Service in the Department of Chemistry at the University of Manchester. EA was performed using a Flash 2000 Thermo Scientific elemental analyzer, and TGA data were obtained with a Mettler Toledo TGA/DSC stare system in the range $30-600{ }^{\circ} \mathrm{C}$ at a heating rate of $10{ }^{\circ} \mathrm{C} \mathrm{min}{ }^{-1}$ under nitrogen flow. Powder XRD analyses were carried out using an XPert diffractometer with a $\mathrm{Cu} \mathrm{K} \alpha 1$ source $(\lambda=1.54059 \AA)$, and the samples were scanned between 10 and $80^{\circ}$; the applied voltage and current were $40 \mathrm{kV}$ and $30 \mathrm{~mA}$, respectively. SEM and EDX spectroscopy analysis were carried out using TESCAN MIRA3 FEG-SEM. Raman spectra were measured using a Renishaw 1000 Micro-Raman System equipped with a $514 \mathrm{~nm}$ laser. Single-crystal XRD data for all the complexes were obtained using Mo $\mathrm{K} \alpha$ or $\mathrm{Cu} \mathrm{K} \alpha$ radiation on a Rigaku FR-X diffractometer. The structures were solved by the SHELXL (Sheldrick, 2015) program. $^{35}$ Non-hydrogen atoms were refined with anisotropic atomic displacement parameters. Hydrogen atoms were placed in calculated positions, assigned isotropic thermal parameters, and allowed to ride on their parent carbon atoms. Crystals suitable for single-crystal XRD were grown using vapor diffusion of hexane into a solution of the requisite metal xanthate in acetone.

Synthesis of $\left[\mathrm{Mn}\left(\mathrm{S}_{2} \mathrm{COMe}\right)_{2} \cdot(\mathrm{TMEDA})\right]$ (1). Potassium methylxanthate was prepared according to the previous 
publications. ${ }^{19,25}$ In brief, potassium hydroxide (0.76 g, 13.63 mmol) was dissolved in excess methanol and stirred for $2 \mathrm{~h}$ at room temperature, followed by cooling to $0{ }^{\circ} \mathrm{C}$. Carbon disulfide (1.04 g, $0.83 \mathrm{~mL}, 13.63 \mathrm{mmol}$ ) was added dropwise to the stirred methanolic solution and stirred for $1 \mathrm{~h}$. An aqueous solution of $\mathrm{Mn}\left(\mathrm{CH}_{3} \mathrm{COO}\right)_{2} \cdot 4 \mathrm{H}_{2} \mathrm{O}(1.6 \mathrm{~g}, 6.8 \mathrm{mmol})$ in $50 \mathrm{~mL}$ of water was added dropwise to the reaction mixture, which was stirred for $30 \mathrm{~min}$ to form a brown/yellow solution. TMEDA $(0.79 \mathrm{~g}, 6.76 \mathrm{mmol})$ was added to the solution while stirring for $1 \mathrm{~h}$ to produce a brown precipitate. The brown precipitate was collected by vacuum filtration and washed with deionized water. The final product was dried in vacuo overnight and was subsequently recrystallized from acetone. Yield: $83.5 \%$ (3.5 g). mp: $138{ }^{\circ} \mathrm{C}$. Elemental analysis: calc (\%): C, 31.17; H, 5.76; S, 33.22; N, 7.27; Mn, 14.27\%. Found (\%): C, 30.98; H, 5.56; S, 33.22; N, 7.02; Mn, 13.94\%. IR $\left(\nu_{\max } / \mathrm{cm}^{-1}\right): 2995$ (w), 1140-1193 (s), 1037 (s).

Synthesis of $\left[\mathrm{Mn}\left(\mathrm{S}_{2} \mathrm{COEt}\right)_{2} \cdot(\mathrm{TMEDA})\right]$ (2). 2 was prepared as $\mathbf{1}$ except that excess ethanol was used in place of methanol. Yield: $88.1 \%$ (3.7 g). mp: $137{ }^{\circ} \mathrm{C}$. Elemental analysis: calc (\%): C, 34.86; H, 6.34; S, 30.96; N, 6.78; Mn, $13.30 \%$ (12.2 g). Found (\%): C, 34.94; H, 6.28; S, 31.26; N, 6.70; Mn, 13.01\%. IR $\left(\nu_{\max } / \mathrm{cm}^{-1}\right): 2980(\mathrm{w}), 1142-1185(\mathrm{~s})$, 1032 (s).

Synthesis of $\left[\mathrm{Mn}\left(\mathrm{S}_{2} \mathrm{CO}^{n} \mathrm{Pr}\right)_{2} \cdot(\mathrm{TMEDA})\right]$ (3). 3 was prepared as $\mathbf{1}$ except using $n$-propanol in place of methanol. Yield: $77.1 \%(3.8 \mathrm{~g})$. mp: $134{ }^{\circ} \mathrm{C}$. Elemental analysis: calc (\%): C, 38.09; H, 6.86; S, 29.00; N, 6.35; Mn, 12.46\%. Found (\%): C, 37.88; H, 6.67; S, 29.37; N, 6.12; Mn, 12.18\%. IR ( $\nu_{\max } /$ $\left.\mathrm{cm}^{-1}\right): 2968(\mathrm{w}), 1145-1179(\mathrm{~s}), 1043(\mathrm{~s})$.

Synthesis of $\left[\mathrm{Mn}\left(\mathrm{S}_{2} \mathrm{CO}^{n} \mathrm{But}_{2} \cdot(\mathrm{TMEDA})\right]\right.$ (4). 4 was prepared as $\mathbf{1}$ except using $n$-butanol in place of methanol. Yield: $76.3 \%$ (4.1 g). mp: $85^{\circ} \mathrm{C}$. Elemental analysis: calc (\%): C, 40.93; H, 7.30; S, 27.26; N, 5.97; Mn, 11.71\%. Found (\%): C, 40.78; H, 7.15; S, 27.58; N, 5.61; Mn, $11.55 \%$. IR ( $\nu_{\max }$ ) $\left.\mathrm{cm}^{-1}\right): 2958(\mathrm{w}), 1043(\mathrm{~s}), 1142-1180(\mathrm{~s})$.

Synthesis of $\left[\mathrm{Mn}\left(\mathrm{S}_{2} \mathrm{CO}{ }^{n} \text { Pent }\right)_{2} \cdot(\mathrm{TMEDA})\right]$ (5). The complex $\mathbf{5}$ was prepared as for $\mathbf{1}$ except using $n$-pentanol in place of methanol. Yield: $78.3 \%$ (4.5 g). mp: $65^{\circ} \mathrm{C}$. Elemental analysis: calc (\%): C, 43.45; H, 7.70; S, 25.73; N, 5.63; Mn, $11.05 \%$. Found (\%): C, 43.41; H, 7.69; S, 25.98; N, 5.42; Mn, $10.86 \%$. IR $\left(\nu_{\max } / \mathrm{cm}^{-1}\right): 2952(\mathrm{w}), 1040(\mathrm{~s}), 1145-1180(\mathrm{~s})$.

Synthesis of $\left[\mathrm{Mn}\left(\mathrm{S}_{2} \mathrm{CO}{ }^{{ }^{n} \mathrm{Hex}}\right)_{2} \cdot(\mathrm{TMEDA})\right]$ (6). 6 was prepared as $\mathbf{1}$ except using $n$-hexanol in place of methanol. Yield: $82.9 \%$ ( $5.1 \mathrm{~g})$. mp: $63{ }^{\circ} \mathrm{C}$. Elemental analysis: calc (\%): C, 45.70; H, 8.06; S, 24.35; N, 5.33; Mn, 10.46\%. Found (\%): C, 45.30; H, 7.99; S, 24.32; N, 5.01; Mn, $10.20 \%$. IR ( $\nu_{\max }$ ) $\left.\mathrm{cm}^{-1}\right): 2952(\mathrm{w}), 1038(\mathrm{~s}), 1142-1182(\mathrm{~s})$.

Synthesis of $\left[\mathrm{Mn}\left(\mathrm{S}_{2} \mathrm{CO}{ }^{n} \mathrm{Oct}\right)_{2} \cdot(\mathrm{TMEDA})\right]$ (7). 7 was prepared as $\mathbf{1}$ except using $n$-octanol in place of methanol. Yield: $80.9 \%$ (5.5 g). mp: $60{ }^{\circ} \mathrm{C}$. Elemental analysis: calc (\%): C, 49.55; H, 8.67; S, 22.00; N, 4.82; Mn, 9.45\%. Found (\%): C, 49.05; H, 8.42; S, 21.91; N, 4.65; Mn, 9.28\%.

Synthesis of MnS NCs by Hot Injection Thermolysis. The MnS NCs were synthesized by dispersing manganese alkylxanthate $(0.2 \mathrm{~g})$ in $2.0 \mathrm{~mL}$ of TOP and then injected into $8.0 \mathrm{~mL}$ of preheated oleylamine (OLA) at $230{ }^{\circ} \mathrm{C}$ with continuous stirring under a nitrogen atmosphere. The temperature was maintained at $230{ }^{\circ} \mathrm{C}$ for $30 \mathrm{~min}$, after which the reaction mixture was allowed to cool to room temperature by removal from the heat source. Methanol (12.0 $\mathrm{mL}$ ) was added to the reaction mixture, and the precipitate was collected by centrifugation.
Synthesis of MnS NCs by Solventless Thermolysis. A total of $0.4 \mathrm{~g}$ of manganese alkylxanthate was placed in a furnace tube under a stream of argon $\left(300 \mathrm{~cm}^{3} \mathrm{~min}^{-1}\right)$. The furnace tube was subsequently heated to $350{ }^{\circ} \mathrm{C}$, held at this temperature for $1 \mathrm{~h}$, and allowed to cool to room temperature.

Deposition of MnS Films by Doctor Blading. In a typical deposition process, $0.02 \mathrm{~g}$ of manganese alkylxanthate was added to $0.2 \mathrm{~mL}$ of THF to form a slurry. The as-prepared complex slurry was pasted on a cleaned glass substrate and distributed uniformly on the glass substrates using a doctor blade made up of stainless steel to form wet thin films of $\mathrm{MnS}$. The films were then placed into furnace tube which was then heated to $350{ }^{\circ} \mathrm{C}$ for $1 \mathrm{~h}$ under a stream of argon $\left(300 \mathrm{~cm}^{3}\right.$ $\left.\min ^{-1}\right)$.

\section{ASSOCIATED CONTENT}

\section{SI Supporting Information}

The Supporting Information is available free of charge at https://pubs.acs.org/doi/10.1021/acsomega.1c02907.

Crystallographic data for complex $\mathbf{1}$ (CIF)

Crystallographic data for complex 2 (CIF)

Crystallographic data for complex 3 (CIF)

Crystallographic data for complex 4 (CIF)

Crystallographic data for complex 5 (CIF)

Crystallographic data for complex 6 (CIF)

Crystallographic data for complex 7 (CIF)

Crystallographic data, elemental analysis, infrared spectroscopy, XRD, EDX, Raman, and SEM (PDF)

\section{AUTHOR INFORMATION}

\section{Corresponding Author}

David J. Lewis - Department of Materials, University of Manchester, Manchester M13 9PL, U.K.; (1) orcid.org/00000001-5950-1350; Email: david.lewis-4@manchester.ac.uk

\section{Authors}

Abdulaziz M. Alanazi - Department of Chemistry, University of Manchester, Manchester M13 9PL, U.K.; Present Address: Department of Chemistry, Islamic university, Prince Naif Ibn Abdulaziz Rd, Madinah, 42351, Saudi Arabia

Paul D. McNaughter - Department of Chemistry, University of Manchester, Manchester M13 9PL, U.K.; (1) orcid.org/ 0000-0002-9330-389X

Firoz Alam - Department of Chemistry, University of Manchester, Manchester M13 9PL, U.K.

Inigo J. Vitorica-yrezabal - Department of Chemistry, University of Manchester, Manchester M13 9PL, U.K.

George F. S. Whitehead - Department of Chemistry, University of Manchester, Manchester M13 9PL, U.K.; - orcid.org/0000-0003-1949-4250

Floriana Tuna - Department of Chemistry, University of Manchester, Manchester M13 9PL, U.K.

Paul O'Brien - Department of Chemistry, University of Manchester, Manchester M13 9PL, U.K.; Department of Materials, University of Manchester, Manchester M13 9PL, U.K.; (1) orcid.org/0000-0001-8744-9174

David Collison - Department of Chemistry, University of Manchester, Manchester M13 9PL, U.K.

Complete contact information is available at:

https://pubs.acs.org/10.1021/acsomega.1c02907 


\section{Author Contributions}

The manuscript was written through contributions of all authors. All authors have given approval to the final version of the manuscript.

\section{Funding}

A.A. is thankful to the Ministry of Higher Education in Saudi Arabia for funding and the University of Islamic, Saudi Arabia, for permission to study in the United Kingdom. We acknowledge the EPSRC National Research Facility for EPR Spectroscopy (NS/A000055/1) at the University of Manchester for support with magnetic and EPR measurements. D.J.L., P.D.M., and F.A. acknowledge EPSRC grants EP/ R020590/1 and EP/R022518/1.

\section{Notes}

The authors declare no competing financial interest.

\section{ACKNOWLEDGMENTS}

We thank Salman Alanazi for useful comments.

\section{REFERENCES}

(1) Ferretti, A. M.; Mondini, S.; Ponti, A. Manganese Sulfide (MnS) Nanocrystals: Synthesis, Properties, and Applications. Advances in Colloid Science; Elsevier, 2017; pp 121-123.

(2) Yang, X.; Wang, Y.; Wang, K.; Sui, Y.; Zhang, M.; Li, B.; Ma, Y.; Liu, B.; Zou, G.; Zou, B. Polymorphism and Formation Mechanism of Nanobipods in Manganese Sulfide Nanocrystals Induced by Temperature or Pressure. J. Phys. Chem. C 2012, 116, 3292-3297.

(3) Yang, X.; Wang, Y.; Sui, Y.; Huang, X.; Cui, T.; Wang, C.; Liu, B.; Zou, G.; Zou, B. Size-Controlled Synthesis of Bifunctional Magnetic and Ultraviolet Optical Rock-Salt MnS Nanocube Superlattices. Langmuir 2012, 28, 17811-17816.

(4) Zheng, Y.; Cheng, Y.; Wang, Y.; Zhou, L.; Bao, F.; Jia, C. Metastable $\gamma$-MnS Hierarchical Architectures: Synthesis, Characterization, and Growth Mechanism. J. Phys. Chem. B 2006, 110, 82848288

(5) Zhang, N.; Yi, R.; Wang, Z.; Shi, R.; Wang, H.; Qiu, G.; Liu, X. Hydrothermal synthesis and electrochemical properties of alphamanganese sulfide submicrocrystals as an attractive electrode material for lithium-ion batteries. Mater. Chem. Phys. 2008, 111, 13-16.

(6) Danielian, A.; Stevens, K. W. H. Exchange Interactions in the Polymorphic Forms of MnS. Proc. Phys. Soc. 1961, 77, 124-128.

(7) Kan, S.; Felner, I.; Banin, U. Synthesis, characterization, and magnetic properties of $\alpha-\mathrm{MnS}$ nanocrystals. Isr. J. Chem. 2001, 41, $55-62$.

(8) Kavcı, O.; Cabuk, S. First-principles study of structural stability, elastic and dynamical properties of MnS. Comput. Mater. Sci. 2014, 95, 99-105.

(9) Yu, X.; Li-yun, C.; Jian-feng, H.; Jia, L.; Jie, F.; Chun-yan, Y. Influence of $\mathrm{S} / \mathrm{Mn}$ molar ratio on the morphology and optical property of $\gamma-\mathrm{MnS}$ thin films prepared by microwave hydrothermal. $J$. Alloys Compd. 2013, 549, 1-5.

(10) Zhang, Y.; Wang, H.; Wang, B.; Yan, H.; Yoshimura, M. Lowtemperature hydrothermal synthesis of pure metastable $\gamma$-manganese sulfide (MnS) crystallites. J. Cryst. Growth 2002, 243, 214-217.

(11) Gümüş, C.; Ulutaş, C.; Esen, R.; Özkendir, O.; Ufuktepe, Y. Preparation and characterization of crystalline $\mathrm{MnS}$ thin films by chemical bath deposition. Thin Solid Films 2005, 492, 1-5.

(12) Ren, Y.; Gao, L.; Sun, J.; Liu, Y.; Xie, X. Facile synthesis of gamma-MnS hierarchical nanostructures with high photoluminescence. Ceram. Int. 2012, 38, 875-881.

(13) Jiang, J.; Yu, R.; Zhu, J.; Yi, R.; Qiu, G.; He, Y.; Liu, X. Shapecontrolled synthesis and properties of manganese sulfide microcrystals via a biomolecule-assisted hydrothermal process. Mater. Chem. Phys. 2009, 115, 502-506.
(14) Wang, S.; Li, K.; Zhai, R.; Wang, H.; Hou, Y.; Yan, H. Synthesis of metastable $\gamma$-manganese sulfide crystallites by microwave irradiation. Mater. Chem. Phys. 2005, 91, 298-300.

(15) Joo, J.; Na, H. B.; Yu, T.; Yu, J. H.; Kim, Y. W.; Wu, F.; Zhang, J. Z.; Hyeon, T. Generalized and Facile Synthesis of Semiconducting Metal Sulfide Nanocrystals. J. Am. Chem. Soc. 2003, 125, 1110011105

(16) Puglisi, A.; Mondini, S.; Cenedese, S.; Ferretti, A. M.; Santo, N.; Ponti, A. Monodisperse Octahedral $\alpha-\mathrm{MnS}$ and $\mathrm{MnO}$ Nanoparticles by the Decomposition of Manganese Oleate in the Presence of Sulfur. Chem. Mater. 2010, 22, 2804-2813.

(17) Tian, Q.; Tang, M.; Jiang, F.; Liu, Y.; Wu, J.; Zou, R.; Sun, Y.; Chen, Z.; Li, R.; Hu, J. Large-scaled star-shaped $\alpha$-MnS nanocrystals with novel magnetic properties. Chem. Commun. 2011, 47, 81008102.

(18) Téllez, C. A. S.; Costa, A. C.; Mondragón, M. A.; Ferreira, G. B.; Versiane, O.; Rangel, J. L.; Lima, G. M.; Martin, A. A. Molecular structure, natural bond analysis, vibrational and electronic spectra, surface enhanced Raman scattering and Mulliken atomic charges of the normal modes of $\left[\mathrm{Mn}(\mathrm{DDTC})_{2}\right]$ complex. Spectrochim. Acta, Part A 2016, 169, 95-107.

(19) Alderhami, S. A.; Collison, D.; Lewis, D. J.; McNaughter, P. D.; O’Brien, P.; Spencer, B. F.; Vitorica-Yrezabal, I.; Whitehead, G. Accessing $\gamma-\mathrm{Ga}_{2} \mathrm{~S}_{3}$ by solventless thermolysis of gallium xanthates: a low-temperature limit for crystalline products. Dalton Trans. 2019, 48, 15605-15612.

(20) Saah, S. A.; McNaughter, P. D.; Malik, M. A.; Awudza, J. A. M.; Revaprasadu, N.; O'Brien, P. $\mathrm{PbS}_{\mathrm{x}} \mathrm{Se}_{1-\mathrm{x}}$ thin films from the thermal decomposition of lead(II) dodecylxanthate and bis(N,N-diethyl-N' naphthoylselenoureato)lead(II) precursors. J. Mater. Sci. 2018, 53, 4283-4293.

(21) McNaughter, P. D.; Bear, J. C.; Mayes, A. G.; Parkin, I. P.; O'Brien, P. The in situ synthesis of PbS nanocrystals from lead(II) noctylxanthate within a 1,3-diisopropenylbenzene-bisphenol A dimethacrylate sulfur copolymer. R. Soc. Open Sci. 2017, 4, 170383-170396.

(22) Al-Shakban, M.; Matthews, P. D.; Deogratias, G.; McNaughter, P. D.; Raftery, J.; Vitorica-Yrezabal, I.; Mubofu, E. B.; O’Brien, P. Novel Xanthate Complexes for the Size-Controlled Synthesis of Copper Sulfide Nanorods. Inorg. Chem. 2017, 56, 9247-9254.

(23) Alanazi, A. M.; Alam, F.; Salhi, A.; Missous, M.; Thomas, A. G.; O'Brien, P.; Lewis, D. J. A molecular precursor route to quaternary chalcogenide CFTS $\left(\mathrm{Cu}_{2} \mathrm{FeSnS}_{4}\right)$ powders as potential solar absorber materials. RSC Adv. 2019, 9, 24146-24153.

(24) Boadi, N. O.; Malik, M. A.; O’Brien, P.; Awudza, J. A. M. Single source molecular precursor routes to lead chalcogenides. Dalton Trans. 2012, 41, 10497.

(25) McNaughter, P. D.; Saah, S. A.; Akhtar, M.; Abdulwahab, K.; Malik, M. A.; Raftery, J.; Awudza, J. A. M.; O’Brien, P. The effect of alkyl chain length on the structure of lead(ii) xanthates and their decomposition to $\mathrm{PbS}$ in melt reactions. Dalton Trans. 2016, 45, $16345-16353$.

(26) Lewis, E. A.; McNaughter, P. D.; Yin, Z.; Chen, Y.; Brent, J. R.; Saah, S. A.; Raftery, J.; Awudza, J. A. M.; Malik, M. A.; O’Brien, P.; Haigh, S. J. In Situ Synthesis of PbS Nanocrystals in Polymer Thin Films from Lead(II) Xanthate and Dithiocarbamate Complexes: Evidence for Size and Morphology Control. Chem. Mater. 2015, 27, 2127-2136.

(27) Câmpian, M. V.; Haiduc, I.; Tiekink, E. R. T. Crystal and Molecular Structures of Two 1:1 Adducts of bis(O-ethyl dithiocarbonato-S, $\left.\mathrm{S}^{\prime}\right)$ manganese(II): $\mathrm{Mn}\left(\mathrm{S}_{2} \mathrm{COCH}_{2} \mathrm{CH}_{3}\right)_{2}$ (1,10-phenanthroline $)$ and $\mathrm{Mn}\left(\mathrm{S}_{2} \mathrm{COCH}_{2} \mathrm{CH}_{3}\right)_{2}$ (2,2'-bipyridyl). J. Chem. Crystallogr. 2010, 40, 1029-1034.

(28) Bondi, A. van der Waals Volumes and Radii. J. Phys. Chem. 1964, 68, 441-451.

(29) Khan, M. D.; Akhtar, M.; Malik, M. A.; Revaprasadu, N.; O'Brien, P. New Examples of Phase Control in the Preparation of Copper Sulfide Nanoparticles and Deposition of Thin Films by 
AACVD from Bis(piperidinedithiocarbamato)copper(II) Complex. ChemistrySelect 2018, 3, 2943-2950.

(30) Mntungwa, N.; Khan, M. D.; Mlowe, S.; Revaprasadu, N. A simple route to alkylamine capped antimony nanoparticles. Mater. Lett. 2015, 145, 239-242.

(31) Arul, N. S.; Han, J. I.; Mangalaraj, D. Fabrication of highly flexible conducting electrode based on $\mathrm{MnS}$ nanoparticles/graphite/ scotch tape for supercapacitor applications. J. Mater. Sci.: Mater. Electron. 2018, 29, 1636-1642.

(32) Dhandayuthapani, T.; Girish, M.; Sivakumar, R.; Sanjeeviraja, C.; Gopalakrishnan, R. Metastable MnS films prepared by the addition of EDTA using chemical bath deposition technique. Int. J. ChemTech Res. 2015, 7, 974-978.

(33) Corliss, L.; Elliott, N.; Hastings, J. Magnetic Structures of the Polymorphic Forms of Manganous Sulfide. Phys. Rev. 1956, 104, 924-928.

(34) Lian, J.; Duan, X.; Ma, J.; Peng, P.; Kim, T.; Zheng, W. Hematite $\left(\alpha-\mathrm{Fe}_{2} \mathrm{O}_{3}\right)$ with Various Morphologies: Ionic LiquidAssisted Synthesis, Formation Mechanism, and Properties. ACS Nano 2009, 3, 3749-3761.

(35) Sheldrick, G. M. Crystal structure refinement with SHELXL. Acta Crystallogr., Sect. C: Struct. Chem. 2015, 71, 3-8. 